\title{
Experiência, barbárie, antropofagia: Oswald de Andrade, contemporâneo de Walter Benjamin
}

\section{Bruno Fabri (UFMG)}

Resumo: Nossa proposição para o presente artigo é colocar em evidência os procedimentos modernistas do escritor paulista Oswald de Andrade em consonância com as noções benjaminianas de "experiência" e de "pobreza", bem assinaladas no clássico ensaio de 1933, e que atestariam fortes afinidades entre os dois escritores/pensadores. Lançaremos mão, também, da noção de In-fância, criada por Giorgio Agamben, como uma espécie de desdobramento dessas idéias de Walter Benjamin e que ajudarão a iluminar alguns dos procedimentos da escrita oswaldiana.

Palavras-chave: Experiência; Pobreza; In-fância.

(...) Uma geração que ainda fora à escola num bonde puxado por cavalos viu-se abandonada, sem teto, numa paisagem diferente em tudo, exceto nas nuvens, e em cujo centro, num campo de forças de correntes e explosões destruidoras, estava o frágil e minúsculo corpo humano.

Walter Benjamin, "Experiência e pobreza”, 1933.

\section{Intróito}

A forte filiação da obra de Oswald de Andrade ao modernismo (tanto o brasileiro como o europeu) oferece-nos um aspecto bastante interessante: a configuração - através de sua obra - da experiência de um tempo. A epígrafe acima, de autoria de um contemporâneo de Oswald, explicita de maneira inaudita o que foi para um cidadão das cidades em franco crescimento, nascer no final do século XIX e crescer nas primeiras décadas do século XX. A velocidade das mudanças materiais e políticas dessas primeiras décadas colocaram em xeque toda uma percepção de nosso entorno colocando-nos no cerne do problema da experiência; questão que se tornou a "pedra de toque" do que certamente houve de melhor em termos de manifestações artísticas e intelectuais nesse período.

Neste ensaio buscaremos enfocar a questão da experiência na obra de Oswald de Andrade, mais especificamente em relação a uma possível "formação do olhar" presente em seus escritos entre 1924 e 1933. Poesia (Pau Brasil e Primeiro caderno de poesia do aluno Oswald de Andrade), prosa "experimental" (Memórias sentimentais de João Miramar e Serafim Ponte Grande), além de manifestos ("Poesia Pau Brasil” e “Antropófago"): gêneros e procedimentos diversos para dar conta das possibildades da 
experiência de uma época única na história brasileira e universal. Os procedimentos mais intimamente artísticos, na obra em prosa e poesia são apoiadas politicamente através dos manifestos, lançados em periódicos em 1924 e 1928 respectivamente.

Para isso, nosso texto lançará mão, num primeiro momento, das noções de "pobreza" e de "experiência" enunciadas juntas pela primeira vez no texto "Experiência e pobreza", de Walter Benjamin, de 1933: a positivação de um novo conceito de barbárie que - indiretamente - apoia e é apoiado pelos manifestos "Poesia Pau-Brasil" (1924) e "Antropófago" de 1928. Em outro item, como desdobramento do anterior, apelaremos para uma noção mais ampla de "infância": aspecto que para nós atravessa toda a obra oswaldiana e é o eixo no qual toda a possibilidade de experiência se consolida em forma de imagens tanto em sua poesia como em sua prosa de vanguarda.

\section{As (im)possibilidades da experiência}

Para Walter Benjamin, a experiência - como classicamente a concebíamos não é possível para o homem moderno. Resta para este fazer "tábula rasa" de toda a cultura, pois a experiência já há muito tempo (desde pelo menos o advento da ciência moderna, de acordo com Giorgio Agamben ${ }^{1}$ ) habita uma esfera alijada, desvinculada do humano por conta de uma série de contextos em que a experiência comunicável não é mais possível. Nesse estado de coisas, surge uma nova e positiva forma de bárbaro, posto que este se contenta com "pouco". Este "pouco" ou esta pobreza da experiência "o impele (o bárbaro) a partir para frente, a começar de novo, a contentar-se com pouco, sem olhar nem para a direita nem para a esquerda" ${ }^{2}$. Todo o modernismo, desde as artes plásticas até a literatura, é composta por este tipo de bárbaro que compreende (conscientemente ou não) essa impossibilidade da experiência que habita o coração deste período, marcado pelo "alto capitalismo".

Oswald de Andrade é um desses "bárbaros" que renunciaram às formas clássicas das expressões e dos gêneros literários, sendo assim impelido a produzir uma obra em que a forma e o conteúdo são marcados por descontinuidades evidentes. E este parece ser o mote ideal para engendrar uma discussão sobre o nosso imbróglio identitário que deu azo a discussões sobre uma concepção de "brasilidade" que permeia toda a sua obra, a começar pelo "Manifesto da poesia Pau-Brasil". Ao enunciar "bárbaro e nosso", Oswald, em um só golpe, dá as bases e imprime uma original - e ainda contemporânea “idéia de Brasil" nessa nova ordem moderna, ao qual o brasileiro está inteiramente vocacionado, adaptado já de saída:

O Cabralismo, A civilização dos donatários. A Querência e a Exportação.

Cadernos Benjaminianos, n. 3, Belo Horizonte, jan.-jun. 2011, p.26-33 
O Carnaval. O Sertão e a Favela. Pau-Brasil. Bárbaro e nosso.

(...)

Bárbaros, pitorescos e crédulos. Pau-Brasil. A floresta e a escola. A cozinha, o minério e a dança. A vegetação. Pau-Brasil. ${ }^{3}$

Oswald vislumbrou, como nenhum outro escritor, essa possibilidade da "virada de mesa" em nossa auto-imagem. De país agrário, atrasado, direto para a vanguarda da modernidade graças à característica fundadora do "ser" brasileiro: a pobreza material e imaterial (em relação ao modelo europeu e centralizador), dado que o "grosso" de nossa população - inclusive a maior parte de nossa "elite" - nunca teve (e certamente nunca terá) um acesso, digamos, satisfatório à alta cultura européia. Os poucos que tiveram, a experimentaram de forma enviesada. E a partir de Oswald de Andrade, "antropofágica", ou seja: crítica.

A antropofagia cultural ${ }^{4}$ é signo fundador de nossa nova barbárie, positivada pelo escritor paulista. Esse gesto entra totalmente em consonância com o que Benjamin descreve em seu clássico ensaio, que se constitui num misto entre manifesto e ensaio crítico, dado à natureza programática das várias proposições que figuram em seu texto de 1933. Aqui ele também arrola toda uma "estirpe" de homens modernos que com pouco ou nada construíram, como engenheiros, novas e revolucionárias concepções de mundo através de suas obras.

(...) Queriam uma prancheta: foram construtores. A essa estirpe de construtores pertenceu Descartes, que baseou sua filosofia numa única certeza - penso logo existo - e dela partiu. Também Einstein foi um construtor assim, que subtamente perdeu todo o interesse por todo o universo da física newtoniana, exceto por um único problema - uma pequena discrepância entre as equações de Newton e as observações astronômicas. ${ }^{5}$

Atentemos para o seguinte aspecto: este ensaio de Benajmin não é uma apologia à ignorância como uma forma vulgar de negação da cultura e das pressões do capital. O gesto é o da desconstrução consciente de todo esse edifício do conhecimento e da experiência que, paradoxalmente, agora localiza-se fora de nosso campo de possibilidades de experienciação, blindado, sem a necessidade de nossa intervenção. $O$ gesto passa a ser o da "devoração crítica" desse edifício, assim como prega a antropofagia cultural oswaldiana.

"Só me interessa o que não é meu. Lei do homem. Lei do antropófago"6. eis o emblema do bárbaro moderno inventado por Oswald. Numa chave benjaminiana poderíamos ler da seguinte maneira este emblema antropofágico: "So me interessa o que não é meu e que nunca será. Lei do homem moderno. Lei do antropófago". Assim, o que na verdade obseda esse antropófago é a experiência, paradoxalmente algo que nunca 
poderá possuir de fato. $\mathrm{O}$ antropófago (o bárbaro) nunca terá essa experiência. No máximo ele poderá $f a z e ̂-l a^{7}$ sem nunca torná-la sua realmente, pois a este homem não é mais reservado a possibilidade de uma experiência qualitativa, algo de comunicável num sentido forte do prefixo comum. Ele apenas fará esta experiência, num ciclo em que uma nova tabula rasa será restabelecida no futuro, re-arranjando os elementos, tangenciando - porém nunca realizando - a possibilidade de um comum.

Assim, sob a égide da barbárie antropofágica, se forma a maneira de olhar e conceber imagens próprias da obra de Oswald de Andrade. Essa organização por vezes caótica de seus versos e dos "capítulos" da sua prosa é fruto desta saída estratégica em direção ao bárbaro. Essa organização do olhar sui generis, original, pode ser entendida também como uma "terapêutica", pois ajuda a compreender (ou ao menos caracterizar de forma mais satisfatória) os sucessivos "sustos" causados pela rapidez com que as mudanças materiais e políticas foram se dando nas primeiras décadas do século passado para o jovem Oswald e seus contemporâneos, principalmente os de São Paulo: cidade que sofreu (e ainda sofre) com a brusca industrialização e com o consequente caos populacional e urbano como neste trecho das Memórias sentimentais de João Miramar:

\section{MAÇONARIA}

Avessos aos favores da cidade íamos perna aqui, perna ali eu e Dalbert de sorte excepcional.

Ruas e quartos a chave bars desertos vibrações revoltas adultérios ênfases.

A estacada foi num casarão azul em vol-plané sobre o val-de-lírios inculto do Anhagabaú.

A coroa do Teatro Municipal punha patetismos pretos nos vermelhos da aurora noturna.

O João Jordão que não era artista nem nada aparecia magro e uma tarde arranjou o subsídio governamental para estudar pintura em Paris. ${ }^{8}$

\section{Infância}

Como havíamos reivindicado anteriormente, entendemos que a infância é o locus privilegiado dessa forma de ver e recolher em forma de palavras as sensações provocadas pelo mundo na sensibilidade do literato paulista. Não apenas imagens derivadas de sensações provenientes da infância cronológica do autor, mas, sobretudo de uma infância que é constituinte de uma idéia de "humano", proposta pelo filósofo italiano Giorgio Agamben.

Num esforço de desdobramento da noção benjaminiana de "experiência", Agamben faz uma minuciosa análise das condições da experiência desde a "invenção" da ciência moderna, que teve no ego cogito (eu penso) cartesiano sua pedra fundamental. Tal mudança de paradigma, ou mesmo, tal expropriação da experiência aos humanos foi

Cadernos Benjaminianos, n. 3, Belo Horizonte, jan.-jun. 2011, p.26-33 
descrita através de lances conceituais violentos que caracterizaram o esforço intelectual de René Descartes em excluir tudo o que fosse duvidoso (fantasias, sensações, etc) e que o desviasse do caminho da razão, descritos em Discurso do método. Na ciência moderna, a experiência deu lugar ao experimento cientifico. Ou seja: se não existe a possibilidade da verificação empírica de tal ou qual evento, então ele deve ser rechaçado. Esse aspecto refundou toda uma noção de cultura ocidental, dando inicio à modernidade.

Mas, segundo Agamben, o ego cogito cartesiano é fundado sobre bases puramente linguísticas; não há um alicerce de natureza transcendental ao ego cogito: "Na sua pureza originária, o sujeito cartesiano nada mais é do que o sujeito do verbo, puramente linguístico-funcional..." É sobre essa matéria rarefeita (ou melhor: sobre este ponto arquimediano deslocado) que se sustenta precariamente o homem moderno: o sujeito da linguagem.

Assim, o filósofo italiano conclui - apoiado nos estudos do linguista francês Émile Benveniste - que não existe sujeito fora da linguagem. Mas e a experiência? Como alguma vez ela se realizou se não existe sujeito sem a língua? Existe uma experiência “'muda' no sentido literal do termo, uma in-fância do homem, da qual a linguagem deveria, precisamente, assinalar o limite?"10. Aqui, o Agamben conclui que não existe uma "substância psíquica pré-subjetiva" cronologicamente delineada. $\mathrm{Na}$ verdade existe uma "história transcendental" em que a in-fância (o puramente humano) e a linguagem coexistem desde sempre. E é dessa tensão dialética que se configura todo tipo de experiência através dos tempos até os dias de hoje. $\mathrm{Na}$ verdade, o ponto arquimediano que equilibra os dois pólos dessa tensão é que mudou de posição com o advento da ciência moderna.

Assim, esse olhar, algo original e "terapêutico" das imagens oswaldianas, possuem muito de infantil na materialidade mesma de sua composição textual. A ludicidade, presente em diversos trechos da obra de Oswald, atesta esta tensão dialética que procura uma frincha na dura rocha da linguagem da modernidade, produzindo algo como uma experiência possível. E é pendendo para o pólo da in-fância que esse olhar se forma. Vejamos o seguinte poema de Pau-Brasil:

\section{VÍCIO NA FALA}

Para dizerem milho dizem mio

Para melhor dizem mió

Para pior pió

Para telha dizem teia

Para telhado dizem teiado

E vão fazendo telhados ${ }^{11}$

Cadernos Benjaminianos, n. 3, Belo Horizonte, jan.-jun. 2011, p.26-33 
Neste poema, presente na seção "História do Brasil", podemos verificar não apenas uma crítica bem-humorada da fala cotidiana, mas também um apelo em direção a uma "redução", em direção à uma maior pureza da língua, entendida aqui como uma forma de se trazer de volta seus elementos primais, originários, e, ao mesmo tempo, propor um jogo lúdico: algo próprio dessa in-fância que nos constitui e que Oswald parece ter antevisto. Serafim Ponte Grande também oferece um expediente parecido já nas primeiras páginas:

\section{PRIMEIRO CONTATO DE SERAFIM E A MALÍCIA}

$$
\begin{aligned}
& \mathrm{A}-\mathrm{e}-\mathrm{i}-\mathrm{o}-\mathrm{u} \\
& \quad \mathrm{Ba}-\mathrm{Be}-\mathrm{Bi}-\mathrm{Bo}-\mathrm{Bu} \\
& \quad \mathrm{Ca}-\mathrm{Ce}-\mathrm{Ci}-\mathrm{Co}-\mathrm{Cu}^{12}
\end{aligned}
$$

A prosa e a poesia de Oswald de Andrade retratam bastante bem esta dificuldade em dar conta deste novo barbarismo: é assim que o olhar na obra oswaldiana nos revela, através de jogos lúdicos, infantis, em forma de palavras essa possibilidade de experiência na modernidade: algo fragmentário, caótico, descontinuado. De certa forma, a bárbarie é a busca pela in-fância de nossa expressividade e isso é traduzido em imagens inusitadas. Aspecto que a obra do modernista nos oferece de maneira profícua em seus livros como o trecho a seguir:

\section{BAR}

Dez horas da noite, o relógio farto batia dão! dão! dão! dão! dão! dão! dão! dão! dão! dão!

Cangalhas com sono arrastavam-se para nós finalizando o serão de amor que Rolah por lições inglesas de futuras vogas em Los Angeles me ofertava depois do jantar.

Eu batia o portão caminhando direto à cidade borrada, no chupachupa de um beijo que ela me deixara no fundo revelação da sua estranha natureza feminina.

Encontrava infalháveis a uma mesa promíscua do Pinoni num açúcar de óperas Machado Penumbra e o dr. Pilatos. E maledizíamos com musical whisky e soda.

\section{Conclusão}

Ben Singer chama a atenção para o início do "hiperestímulo sensorial" a que foram submetidos os cidadãos que habitavam as grandes metrópoles na virada do século XIX para o XX. Para Singer, "o indivíduo defrontou-se com uma nova intensidade de estimulação sensorial. A metrópole sujeitou o indivíduo a um bombardeio de impressões, choques e sobressaltos"13. Esse "hiperestímulo" era, em maior parte, originado pelas 
imagens espetaculares dos periódicos, das propagandas e de outros meios. Mas a crescente "mecanização" da vida nas grandes cidades intensificava o caráter cinético do cotidiano e o anseio nervoso por mais e mais estímulos visuais cada vez mais espetaculares: assim, não por acaso, na última década do século XIX, surge o cinema.

É neste contexto, em que nada permanece no mesmo lugar por muito tempo, que a obra de Oswald procura dar a ver alguma possibildade de uma experiência, mesmo que rasa: um expediente tipicamente modernista. Como também é modernista a busca por essas "origens" que ocorre concomitantemente com este acolhimento das novas sensações. Este é o "gesto duplo" do bárbaro moderno: a constituição de um testemunho de uma época passa por esse entrecruzamento espaço-temporal que abole toda forma de cronologia, tomando o tempo e o espaço como pura intensidade. Os escritos de Oswald, procuram, através do olhar deste bárbaro, nos “dar a ver” esta intensidade.

\begin{abstract}
Our proposition for this paper is to highlight the procedures of the modernist writer Oswald de Andrade Sao Paulo with the Benjamin notions of "experience" and "poverty" well-marked on the classic essay of 1933, and that could attest to the strong affinity between two writers / thinkers. We used, too, the notion of infancy, created by Giorgio Agamben, as a kind of unfolding of these ideas of Walter Benjamin and to help illuminate some of the procedures of writing Oswald.
\end{abstract}

Keywords: Experience, Poverty, Infancy.

\title{
Referências Bibliográficas
}

AGAMBEN, Giorgio. Infância e história. Destruição da experiência e origem da história. Trad. Henrique Burigo. Belo Horizonte: UFMG, 2007.

ANDRADE, Oswald de. Manifesto antropófago. In: A utopia antropofágica. São Paulo: Globo, 1995.

ANDRADE, Oswald de. Memórias sentimentais de João Miramar. São Paulo: Globo, 2008.

ANDRADE, Oswald de. Pau-Brasil. São Paulo: Globo, 1990.

ANDRADE, Oswald de. Serafim Ponte Grande. São Paulo: Círculo do livro, s/d.

BENJAMIN, Walter. Experiência e pobreza. In: Obras escolhidas, vol.1. Magia e técnica, arte e política. Trad. Sérgio Paulo Rouanet. São Paulo: Brasiliense, 1985.

SINGER, Ben. Modernidade, hiperestímulo e o início do sensacionalismo popular. In: CHARNEY, Leo; SCHWARTZ, Vanessa R. O cinema e a invenção da vida moderna. São Paulo: Cosac Naify, 2004.

Cadernos Benjaminianos, n. 3, Belo Horizonte, jan.-jun. 2011, p.26-33 


\section{Notas}

${ }^{1}$ Cf. AGAMBEN, Giorgio. Infância e história. Destruição da experiência e origem da história. Trad. Henrique Burigo. Belo Horizonte: UFMG, 2007.

${ }^{2}$ BENJAMIN, Walter. Experiência e pobreza. In: Obras escolhidas, vol.1. Magia e técnica, arte e política. Trad. Sérgio Paulo Rouanet. São Paulo: Brasiliense, 1985, p. 116. ${ }^{3}$ ANDRADE, Oswald de. Pau-Brasil. São Paulo: Globo, 1990, p. 65-66.

${ }^{4}$ Usamos aqui o termo "antropofagia cultural", pois a idéia oswaldiana de "antropofagia" foi inspirada na antropofagia ritual dos índios Tupinambá que habitavam boa parte da costa brasileira, concentrados principalmente onde hoje é a cidade do Rio de Janeiro.

${ }^{5}$ BENJAMIN, Op. Cit. p. 116

${ }^{6}$ ANDRADE, Oswald de. Manifesto antropófago. In: A utopia antropofágica. São Paulo: Globo, 1995, p. 47.

${ }^{7}$ Essa distinção é comentada por AGAMBEN, Op. cit.

${ }^{8}$ ANDRADE, Oswald de. Memórias sentimentais de João Miramar. São Paulo: Globo, 2008, p. 82.

${ }^{9}$ AGAMBEN, Op. Cit., p. 31.

${ }^{10}$ AGAMBEN, Op. Cit., p. 58.

${ }^{11}$ ANDRADE, Oswald de. Pau-Brasil. São Paulo: Globo, 1990, p. 80.

12 ANDRADE, Oswald de. Serafim Ponte Grande. São Paulo: Círculo do livro, s/d, p. 19.

${ }^{13}$ SINGER, Ben. Modernidade, hiperestímulo e o início do sensacionalismo popular. In: CHARNEY, Leo; SCHWARTZ, Vanessa R. O cinema e a invenção da vida moderna. São Paulo: Cosac Naify, 2004, p. 96. 